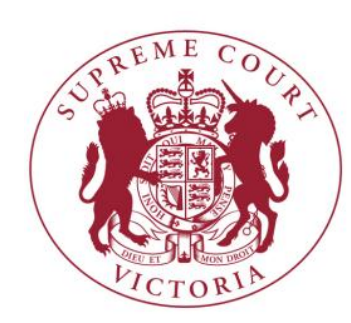

\title{
CONCURRENT EVIDENCE IN THE KILMORE EAST BUSHFIRE PROCEEDING
}

\author{
SIMON MCKENZIE*
}

This paper, the third in a series on the management of expert evidence during the Kilmore East bushfire proceeding, considers the use of the concurrent evidence procedure. During this case, the largest class action in Victoria's history, the parties and the Court were confronted with challenging factual issues that generated a substantial amount of expert evidence. The volume and complexity of this evidence led to the adoption of more innovative methods of managing expert evidence, including hearing the evidence concurrently at trial. This paper considers whether the adoption of the concurrent evidence procedure usefully contributed to the trial. It records the views of a range of participants in the proceeding, including the presiding judge, barristers, solicitors and experts, material gathered in interviews conducted after the case settled. These interviews indicate that the use of concurrent evidence was a success. It was seen as a useful tool to help the Court deal with complex expert evidence. The experience in the Kilmore East bushfire proceeding also illustrated some of the challenges of very large concurrent evidence sessions, including resourcing issues and the need to protect the well-being of the experts. Notwithstanding these concerns, the procedure should be considered by judges in all cases where there are multiple experts giving evidence on the same issues.

\section{CONTENTS}

I. Introduction 2

II. Brief overview of relevant law and scholarship 3

III. Concurrent evidence sessions in the Kilmore East bushfire proceeding

\footnotetext{
${ }^{*}$ BA, LLB (Hons) (Tas); Senior Fellow (Melbourne Law Masters) and PhD Candidate at the University of Melbourne. The support of Justice Rita Zammit and Justice Jack Forrest was invaluable in carrying out this research project. In addition, the assistance and advice of Gary Cazalet at the University of Melbourne as well as Stuart Moran and Katrina Chow at the Supreme Court of Victoria are gratefully acknowledged. The Supreme Court of Victoria funded this research.
}

This paper was published on 13 April 2016. 
A. Impact of a large number of experts giving evidence................................................ 12

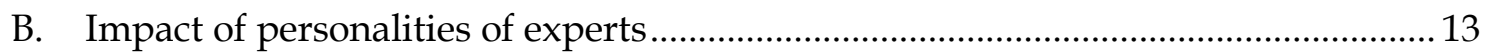

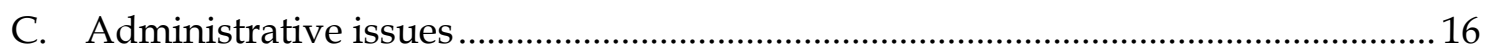

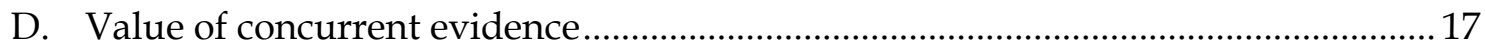

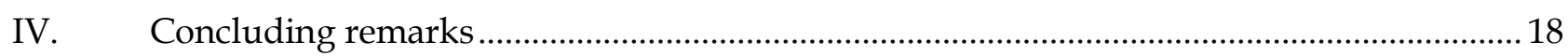

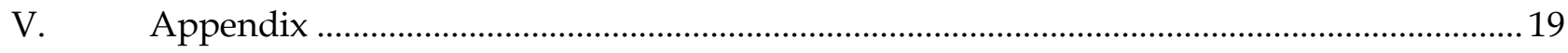

A. Section one: view from the Victorian bench................................................................. 19

1. Level of judicial intervention .............................................................. 20

2. Impact of personalities of experts ......................................................... 22

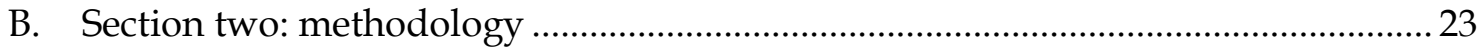

\section{INTRODUCTION}

Perhaps the most important stage of any court's management of expert evidence is at trial. This is when the judge and the parties test the validity of the experts' opinions through examination and cross-examination. Traditionally, evidence is taken from experts one at a time and with the plaintiff and defendant sides presenting their whole cases separately. However, the scale of Matthews $v$ SPI Electricity Pty Ltd (the 'Kilmore East bushfire proceeding') meant that the Court had to adopt non-traditional procedures for hearing expert evidence. The Court heard evidence from the experts concurrently, with some concurrent sessions involving as many as nine experts. This paper - the third in a series on the management of expert evidence in the proceeding assesses the experience of some of the participants during the concurrent evidence sessions and their views about the effectiveness of concurrent evidence in delivering a just result by a just process.

This material was gathered in interviews conducted in person and by email with some of the participants: Justice Jack Forrest (the trial judge), as well as two barristers, two solicitors and two experts. These participants considered hearing evidence concurrently was valuable to the proceedings, making it easier for the judge and parties to assess the persuasiveness of the expert evidence. Compared to the traditional method of giving expert evidence, the participants found it better represented the views of the experts and the areas of their agreement and disagreement between them and saved time. Nevertheless, this powerful procedural tool is not appropriate for every case, and the experience in the Kilmore East bushfire proceeding helps show when it should be used and how a court should manage it. 
The paper focuses on a number of issues. The first section provides a snapshot of the relevant law and scholarship regarding concurrent evidence. It then sets out the participants' view on the level of judicial intervention exercised by Justice Forrest during the concurrent evidence sessions, going on to explore the impact of a large number of experts giving evidence concurrently, the impact of the personalities of experts, as well as other administrative issues such as the quarantining of experts. Finally, it sets out the participants' reflections on the general value of concurrent evidence in this proceeding.

The paper also has an appendix that provides further context and information about concurrent evidence. The first section sets out the thoughts of four Victorian judges, collected in interviews conducted by the author, about when and how courts should use and manage concurrent evidence. The second section sets out the methodology of the paper.

\section{BRIEF OVERVIEW OF RELEVANT LAW AND SCHOLARSHIP}

Concurrent evidence is a procedure where experts give their evidence to the court at the same time. A concurrent evidence session is usually preceded by expert conferences - otherwise known as expert conclaves - where the experts meet and produce a joint report that identifies the areas of agreement and disagreement. Concurrent evidence enables an approach substantially different to the traditional method by which experts gave evidence in court which requires experts to first write reports, and then appear in court giving evidence in chief, being cross-examined and finally re-examined by counsel. This is a time consuming process. The New South Wales Law Reform Commission (NSWLRC) explained concurrent evidence:

... the relevant experts in a particular area are sworn in at one time and remain together in court. The giving of evidence becomes a discussion rather than a series of exchanges between a lawyer and a witness. In the discussion, questions may be asked not only by the lawyers and the judge, but also by one expert of another, a departure from the traditional approach in which only the crossexamining lawyer asks questions. The discussion is focused, highly structured, and controlled by the judge. ${ }^{1}$

According to Justice Hargrave of the Supreme Court of Victoria:

${ }^{1}$ New South Wales Law Reform Commission, Expert Witnesses, Report No 109 (2005), 6.48. 
This is not a passing fad. Practitioners and experts should be in no doubt that courts will continue to adopt this approach in the future, and not just in commercial cases. The landscape will also change for common law cases, and even criminal cases subject to appropriate safeguards. ${ }^{2}$

In Victoria, the Court is able to give directions setting out how experts are to give their evidence, including giving it concurrently. This power was explicitly granted to the courts in Victoria in $\mathrm{s}$ 65K of the Civil Procedure Act 2010 (Vic). This section provides:

1) A court may give any direction it considers appropriate in relation to the giving of evidence by any expert witness at trial.

2) Without limiting subsection (1), the court may direct that any expert witness -

a) Give evidence at any stage of the trial, including after all factual evidence has been adduced on behalf of all parties;

b) Give evidence concurrently with one or more expert witnesses;

c) Give an oral exposition of his or her opinion on any issue;

d) Give his or her opinion on any opinion given by other expert witnesses;

e) Be examined, cross-examined or re-examined in a particular manner or sequence, including by putting to each expert witness, in turn, each issue relevant to one matter or issue at a time;

f) Be permitted to ask questions of any other expert witness who is concurrently giving evidence.

3) A court may question any expert witness to identify the real issues in dispute between 2 or more expert witnesses, including questioning more than one expert witness at the same time.

The relevant Explanatory Memorandum explained the section was to provide the court with the power to "at any time give any direction that it considers appropriate in relation to the giving of expert evidence at trial." 3 This included "innovative approaches to the management of expert evidence" which aimed to "improve the quality and integrity of expert evidence and increase the usefulness of expert evidence to the courts".4

\footnotetext{
2 Justice Kim Hargrave, 'Expert Witnesses/Hot Tubbing', Commercial Court Seminar, Melbourne, 27 October 2010.

${ }^{3}$ Explanatory Memorandum, Civil Procedure Amendment Bill 2012, 7.

${ }^{4}$ Ibid.
} 
Concurrent evidence has been a feature of complex litigation in Australia for many years. ${ }^{5}$ It was introduced in the late 1990s, partly in response to a study that found that the majority of judges felt they did not understand the expert evidence before them, with $20 \%$ admitting they 'often' faced difficulties in evaluating different expert opinions. ${ }^{6}$ It was thought that concurrent evidence would assist judges in this task. ${ }^{7}$

The NSWLRC reported that the experience of the New South Wales Land and Environment Court of concurrent evidence had been very positive as it allowed the experts to answer questions from the court, from the parties and from their colleagues. ${ }^{8}$ The procedure had "overwhelming support" from experts and their professional organisations as they found they were better able to communicate their opinions to the Court, and they also thought there was less chance their opinions would be distorted by the advocate's skills. ${ }^{9}$

The NSWLRC supported the procedure, noting it offered significant potential benefits, including saving time by allowing key points to be quickly identified and discussed. The NSWLRC considered it particularly important that the:

... process moves somewhat away from lawyers interrogating experts towards a structured professional discussion between peers in the relevant field. The experience in the Land and Environment Court indicates that the nature of the evidence is affected by this feature, and that experts typically make more concessions, and state matters more frankly and reasonably, than they might have done under the traditional type of cross-examination. Similarly, it seems that the questions may tend to be more constructive and helpful than the sort of questions sometimes encountered in traditional cross-examination. ${ }^{10}$

The NSWLRC noted that the success of the procedure will depend on the skill of the judge in structuring and controlling the discussion to ensure all points of view are heard and counsel has adequate opportunity to test the expert evidence. ${ }^{11}$

\footnotetext{
${ }^{5}$ For instance, Justice Garry Downes provided a summary of the use of concurrent evidence in the AAT in 'Concurrent Evidence in the Administrative Appeals Tribunal: the New South Wales Experience' (Paper presented at the Australasian Conference of Planning and Environment Courts and Tribunals, Hobart, 27 February 2004).

${ }^{6}$ Mia Livingstone, 'Have we fired the "hired gun"? A critique of expert evidence reform in Australia and the United Kingdom' (2008) 18 JJA 39, 50.

7 Ibid.

${ }^{8}$ New South Wales Law Reform Commission, Expert Witnesses, Report No 109 (2005), 6.50.

${ }^{9}$ Ibid 6.51.

${ }^{10}$ Ibid 6.56 .

11 Ibid 6.57 .
} 
Livingstone found that the majority of commentators supported the procedure as it gave better clarity and coherence to expert evidence, and it assisted judges in understanding expert evidence by presenting the information in a collaborative and connected way. ${ }^{12} \mathrm{~A}$ comprehensive review undertaken by the Administrative Appeals Tribunal (AAT) in 2005 found that $67.2 \%$ of members reported that the quality of expert evidence had improved and $87.9 \%$ of members reported that the task of comparing different experts' evidence on each issue was easier, and $88.1 \%$ of members believed that the decision-making process was enhanced. ${ }^{13}$

Published judicial commentary on the procedure has been favourable. Justice Hargrave identified benefits of the procedure:

[The benefits] can be simply stated. Counsel's job is made easier and less time consuming, in preparation, in conducting cross-examination of experts and preparing final submissions. For the judge, there is an increased burden prior to the trial if the judge is involved in managing the joint report process and in formulating the questions for the joint report; and during the trial the judge must master the material so as to be in position to control the concurrent evidence [...]. However, once the trial is over, the real benefits accrue to the judge. The issues are simplified and the relevant evidence is easy to find. The joint report and the self-contained transcript for each issue make the judgment writing process much easier and assist in decision-making. ${ }^{14}$

Similarly, Justice Peter McClellan said that concurrent evidence allows the courtroom to provide "the decision-making process which professional people conventionally adopt." 15 The evidence session becomes a "discussion in which everyone's views [are] put forward, analysed and debated."16

Some do have concerns about adverse consequences of giving evidence concurrently. Livingstone notes the possibility that a group discussion among experts will result in only the most insistent voices being heard, and the process will advantage experts with dominating and forceful personalities. ${ }^{17}$ There is also the potential for the enhanced role of the judge to cause difficulty. Neil Young QC said that it is important that the "panel discussion is a structured one", with each

\footnotetext{
${ }^{12}$ Mia Louise Livingstone, 'Have we fired the 'hired gun'? A critique of expert evidence reform in Australia and the United Kingdom' (2008) 18 JJA 39, 50.

${ }^{13}$ Ibid 51. Cf the critique of this study in Gary Edmond, 'Judging Surveys: Experts, Empirical Evidence and Law Reform' (2005) 33(1) Federal Law Review 95.

${ }^{14}$ Justice Kim Hargrave, 'Expert Witnesses/Hot Tubbing', Commercial Court Seminar, Melbourne, 27 October 2010.

${ }^{15}$ Justice Peter McClellan, 'Sworn together: A discussion of concurrent evidence' (2009) 93 Precedent 17, 18.

16 Ibid.

17 Justice Kim Hargrave, ‘Expert Witnesses/Hot Tubbing', Commercial Court Seminar, Melbourne, 27 October 2010.
} 
expert able to give their opposing expert opinions "without interruption by the other experts or from the Bench". ${ }^{18} \mathrm{He}$ also said he had seen cases where the judge "tries to control the direction of the debate unduly or intervenes excessively." He said that this can result in "messy and even unintelligible transcript of evidence" due to the missed dialogue or inadequately explained opinions. ${ }^{19}$

Gary Edmonds raises more fundamental questions about the validity of the fears of expert partisanship and bias, arguing they may "not present particularly serious problems in civil cases." 20 He explains that:

Adversarial procedures - which include scope for rigorous cross-examination - constantly remind us of the limitations of expertise; the intractable nature of expert disagreement; the prevalence of alignments, commitments, and interests; and other potentially biasing factors. Expert disagreement creates problems primarily because there are no simple means of resolving disagreement in socially legitimate ways. Attributions of bias (and objectivity and impartiality) are unlikely to produce bright lines for understanding or assessing particular proffers of expert evidence. They are of limited value in determining the reliability of expert-opinion evidence or the authenticity of disagreement and, without more, do not present constructive bases for law reform. ${ }^{21}$

Nevertheless, Livingstone reports that these concerns do not seem to be shared by participants in concurrent evidence sessions. ${ }^{22}$ Justice McClennan, who has been a strong advocate of the procedure, said that the process actually assists those who are shy or indifferent to participate to the structured discussion as the debate will occur on an intellectual level (as opposed to cross examination). ${ }^{23}$ It also allows the judge to observe the experts discuss the matters in issue with each other. ${ }^{24}$

Justice Downes, President of the AAT, said while in his experience most experts "do not deliberately mould their evidence to suit the case of the party retaining them", when this

\footnotetext{
${ }^{18}$ Neil J Young, 'Expert Witnesses: On the Stand or in the Hot Tub - How, When and Why?' (Paper presented to the Commercial Court Seminar, 27 October 2010), [19].

${ }^{19}$ Ibid [20].

${ }^{20}$ Gary Edmond, 'Merton and the Hot Tub: Scientific Conventions and Expert Evidence in Australian Civil Procedure' (2009) 72 Law and Contemporary Problems 159, 188.

${ }^{21} \mathrm{Ibid}, 188$.

${ }^{22}$ Mia Louise Livingstone, 'Have we fired the 'hired gun'? A critique of expert evidence reform in Australia and the United Kingdom' (2008) 18 JJA 39, 50.

${ }^{23}$ Justice Peter McClellan, Concurrent Expert Evidence, keynote address presented at the Medicine and Law Conference, Law Institute of Victoria, 29 November 2007.

${ }^{24}$ Ibid.
} 
happened it was clear from the evidence they adduced..$^{25}$ According to his Honour, this was one of the strengths of the traditional approach: it exposed "different expert points of view for evaluation by the judge." 26 He said that concurrent evidence also allows for the same testing of different expert viewpoints. In addition to this, Justice Downes explained that it "can have a number of virtues" over the traditional approach:

- The evidence on one topic is all given at the same time;

- The process refines the issues to those that are essential;

- Because the experts are confronting one another, they are much less likely to act adversarially;

- A narrowing and refining of areas of agreement and disagreement is achieved before crossexamination; and

- Cross-examination takes place in the presence of all the experts so that they can immediately be asked to comment on the answers of colleagues. ${ }^{27}$

Justice James Allsop, then President of the New South Wales Court of Appeal, wrote that the technique has "great potential", but made the point that for it to be effective, "the judge has to be well prepared and very familiar with the technical issues in order to absorb and participate in the professional exchange." 28 It is also widely thought that the process reduces time, cost and delay by allowing issues to be quickly identified and discussed.29

\section{CONCURRENT EVIDENCE SESSIONS IN THE KILMORE EAST BUSHFIRE PROCEEDING} Justice Forrest was prescriptive as to how the concurrent evidence sessions in the Kilmore East bushfire proceeding would be run. He provided a protocol to the barristers and the experts setting out how each topic would be examined, and the procedure for questioning by the other experts, counsel, the judge and the assessors. His Honour described the process:

We adopted a formula which we applied to expert evidence concurrent sessions whether there were two or eight [experts], which was to allow the expert to make an opening statement and allow counsel calling that expert to ask a few questions, a limited number of questions, perhaps to

\footnotetext{
${ }^{25}$ Justice Garry Downes, 'Problems with expert evidence: Are single or court-appointed experts the answer?' (2006) 15 JJA 185, 186.

${ }^{26}$ Ibid 186.

27 Ibid 188.

${ }^{28}$ James Allsop, ‘The judicial disposition of competition cases' (2010) 17 Competition \& Consumer Law Journal 241.

${ }^{29}$ Mia Louise Livingstone, 'Have we fired the 'hired gun'? A critique of expert evidence reform in Australia and the United Kingdom' (2008) 18 JJA 39, 52.
} 
elucidate on matters in the report, then to allow cross-examination and then to permit the experts to question each other before making closing statements on a particular topic. ${ }^{30}$

Justice Forrest noted it was difficult for him to assess whether the level of judicial control exercised helped the trial to run more effectively, and whether the protocol was adequate in the circumstances. ${ }^{31}$ He nevertheless said the procedure appeared to be very effective. He said that even with the protocol, it was important to be flexible and "from time to time adapt to what might be said. It may well be that you need to change the order in which evidence is being given because [of] the priorities [of the Court] and because of the way in which the evidence has emerged." 32

Justice Forrest said one "drawback" to the procedure was the need for the judge to be very proactive in managing the concurrent evidence sessions:

In each of the bushfire cases, it was necessary to be on top of the reports and the joint reports and ensure, as best we could, the judge take, at least at the outset, an active role in adducing the evidence and extracting from the experts what their views were on particular topics. It was necessary to draw up a list of topics to be considered by the experts and get them to go through each topic in order. To do that, it was necessary to understand the expert reports and the likely views or opposing views of the experts. ${ }^{33}$

Through this substantial amount of work he acquired a sophisticated understanding of the expert evidence prior to the concurrent evidence session. He said it enabled him to seek clarification as early as possible from the experts regarding any confusion or misunderstanding. To this end, Justice Forrest had some of the experts prepare a two-day tutorial on material that would be the subject of the most difficult part of the expert evidence. He said this was quite effective in helping to better understand the material. ${ }^{34}$

The legal practitioners who were interviewed said the level of judicial involvement in the concurrent evidence session was appropriate. One barrister explained how it worked in practice:

The judge had done his reading, he'd thought about the agenda issues, he circulated agendas weeks in advance of the concurrent evidence sessions. The parties [then] got an opportunity to feed in to the agendas (which was helpful), and by the time the experts hopped into the box, the judge was across their reports [...] [the judge] led off with the questions, and then counsel got an opportunity, and then the judge would jump in again as he saw fit. [...] [T]he protocol that Justice Forrest laid out

\footnotetext{
${ }^{30}$ Interview with Justice J. Forrest (8 August 2014, Supreme Court of Victoria, Melbourne).

${ }^{31} \mathrm{Ibid}$.

32 Ibid.

33 Ibid.

${ }^{34}$ Ibid.
} 
for the procedure to be followed during the concurrent evidence sessions worked, I thought, very well. And it should form the basis for the standard model in the future. ${ }^{35}$

The other barrister agreed, saying the protocol Justice Forrest put in place for concurrent evidence, and his interventions during the concurrent evidence sessions, were "critical" and "excellent" as it ensured the Court had control over the process. ${ }^{36}$ He said the protocol would work with any number of experts:

I can't see a reason why you would change those sorts of protocol, whether you had three experts for a subject area, or eight or ten. I mean obviously the problems get magnified the larger the number, and for cross-examining counsel you've got to be fairly nimble in terms of how you deal with a larger number, but there you go. I think the process worked extremely well and I can't think of a good reason to change it, quite frankly. ${ }^{37}$

Both barristers emphasised that concurrent evidence required the Judge to do a considerable amount of preparation before trial. One barrister said you needed "a judge who has mastered the material, and who is not shy about exercising his or her control" to make sure the experts gave useful evidence. ${ }^{38}$ However, the other barrister noted that concurrent evidence requires more work from the judge "only in the sense that it requires the time before the evidence [is given in court] rather than time after the evidence." 39 It means that the judge knows the questions that he or she will need answered when the expert is giving the evidence, rather than realising the evidence "hasn't answered the questions [when] he tried to read the transcript six months later." 40 One solicitor raised the inability to re-examine as an issue: in the trial it was "a function that in practice was left to the experts in the process of summing up at the end of each question." $41 \mathrm{He}$ said that while this was useful it should "not replace the role of counsel in leading evidence that is relevant to the determination of the issues in dispute in the proceeding" as it is "a function that cannot be delegated to non-legal experts". ${ }^{42}$

The experts seemed mostly satisfied with the overall approach of Justice Forrest. One expert said Justice Forrest mainly listened to the evidence, and "did not intrude significantly while the experts

\footnotetext{
35 Interview with barrister involved in proceeding (Morning of 24 February 2015, Melbourne) ('Interview with barrister $\mathrm{A}^{\prime}$ ).

${ }^{36}$ Interview with barrister involved in proceeding (Afternoon of 24 February 2015, Melbourne) ('Interview with barrister $\mathrm{B}^{\prime}$ ).

37 Ibid.

38 Ibid.

${ }^{39}$ Interview with barrister A, above n 35.

40 Ibid.

${ }^{41}$ Interview with solicitor involved in proceeding (9 June 2015, by letter) ('Interview with solicitor B').

42 Ibid.
} 
were giving their evidence and replying to the lawyers' questions." 43 He did, however, say that experts were not always able to provide to the Court evidence they considered relevant. He noted that one expert wished to present papers to the Court, but was at first denied and later on permitted to submit summaries. ${ }^{4}$ The other expert said the level of judicial intervention was appropriate, saying that Justice Forrest did a "really great job of giving people a break, and letting us take a beating when appropriate." He said that the "occasional direct judicial questioning or comment was always appreciated, and [I] admired the intellect and social intelligence of the bloke." 45

The lawyers and the experts supported allowing the experts to ask questions of one another. One barrister said that experts asking each other questions "was always exciting", and that it helped the parties in a number of ways. It meant that if the cross-examining counsel was given an answer he or she did not understand, but was nevertheless incorrect or unsustainable, they had their expert there to bring it to the attention of the Court. ${ }^{46}$ The barrister explained:

[I]t imposes an actual discipline on all experts in that they can't put one over counsel because [it] will be picked up by the other side's experts [who have] the capacity to ask each other questions [...]. Whereas if I was just cross-examining a [...] mechanical engineer there might be something there that I hadn't heard of, [or was] outside my area of expertise or preparation, and he or she might get away with it. But they can't get away with it as easily in a concurrent evidence session. ${ }^{47}$

He said he was "very happy" to have "my own experts there picking up on a ridiculous answer that a witness gave to one of my questions that I didn't pick up on." $48 \mathrm{He}$ described it as a "good insurance policy for counsel." 49

One expert explained that he was strategic about when he questioned other experts, and said that he "used these questions only when I knew the outcome to emphasise particular points within the discussion." $50 \mathrm{He}$ said at one stage of the evidence he asked another expert whether "a particular nuance of their analysis" was a "done-deal", knowing from previous discussions with that expert that "the topic was not a done-deal at all". ${ }^{51} \mathrm{He}$ said that the:

\footnotetext{
${ }^{43}$ Interview with expert (23 February 2015, by email) ('Interview with expert A').

${ }^{44}$ Ibid.

45 Interview with expert (24 March 2015, by email) ('Interview with expert B').

46 Interview with barrister B, above $\mathrm{n} 36$.

47 Ibid.

48 Ibid.

${ }^{49}$ Ibid.

${ }^{50}$ Interview with expert B, above $\mathrm{n} 45$.

${ }^{51}$ Ibid.
} 
[...] flustered half answer with the introduction of new material highlighted that this was not at all a done-deal, and the deliberate coupling to the argument in the question was sneaky. Justice Forrest saw it all for what it was and stopped further questions. 52

Reflecting on this experience, he said that "there is something in the gaming of the rules that biases this to clever witnesses that seems inappropriate." 53 He thought that if the experts had competitive personalities, "any rule of engagement will be analysed and used, [and] lenience may give unfair opportunity." $54 \mathrm{He}$ said that "the strategies and casual language outlined were developed by thinking [on] the communication problem overnight [while] editing multiple drafts of questions and statements" and that it was "a developed strategy for communication." But, he did not think that, on balance, this was a problem: "these opportunities were so rare that I felt these opportunities added to the process by providing a vector for a witness to undermine incorrect or weak arguments as they developed." 55 This shows that expert witnesses can sometimes be as tactically minded as the lawyers, and that the process allows them to exercise this skill.

\section{A. Impact of a large number of experts giving evidence}

The most significant impact of the large number of experts giving evidence concurrently was the time each concurrent evidence session took. Some concurrent evidence sessions went for over a week, which was particularly difficult for the experts who were sitting in the session each day. In addition, Justice Forrest said that managing eight or nine experts at once was "very difficult" and that even if he were on top of the material, it would be better to "be handling expert evidence in a concurrent evidence session of three or four people rather than double that." 56

The legal practitioners interviewed saw this as an inevitable consequence of the scale and complexity of the expert evidence, and were not overly concerned. The benefits of concurrent evidence meant that it was worthwhile. One solicitor explained that he thought the Court did "pretty well." He said that:

The way I would test [the process is to ask whether] I [was] satisfied at the end of the process that the half-baked ones looked half-baked, that the true experts truly looked expert, I thought the answer was by and large yes. It was pretty apparent to everyone who knew their stuff, who was

\footnotetext{
52 Ibid.

53 Ibid.

54 Ibid.

55 Ibid.

56 Interview with Justice J Forrest, above n 30.
} 
pretty good but not quite as good, and who maybe should have been doing something else with their time. ${ }^{57}$

Similarly, the other solicitor said that it "worked reasonably well" but that "it may have been possible to reconfigure those sessions into smaller groupings, which may have been more beneficial." 58

The number of experts made the job of the barristers more challenging. One barrister said that it was "extremely difficult" and that it required him to "be very flexible" and "much more dynamic" than during a traditional cross-examination. He said "you had to move with the flow a bit sometimes what was said during the concurrent evidence session [...] came out of left field."59

The large and lengthy concurrent evidence sessions were difficult for the experts as well. One said the amount of time it required was challenging:

I expect that the process was economical for the court, but it was an uneconomical use of time for the experts. All experts had deadlines and tasks, related to their university or industrial roles, and were clearly over-burdened by having the court related work on top of that. The questions from the assessors required "homework" most evenings to prepare for the responses the next day. Overall compared to normal working environments the court appears extremely inefficient. ${ }^{60}$

The other expert said large concurrent evidence sessions resulted in "a lot of 'dead-time' in working through each witness", and that "if the topic areas were more focussed this would have made a smaller group and increased efficiency." 61

\section{B. Impact of personalities of experts}

Justice Forrest said that the different personalities of the experts had an "interesting" impact on the proceedings. Some experts were more confident in how they expressed themselves, and it was clear that some had dominant personalities. There were "robust differences of opinion" during the concurrent evidence which was what "one might hope for." He was not convinced that this meant "it was possible for one person [...] to dominate the session." 62 While on some occasions he had to step in to ensure that all the experts had the opportunity to contribute, he said that the protocol

\footnotetext{
${ }^{57}$ Interview with solicitor involved in proceeding (20 February 2015, Melbourne) ('Interview with solicitor $\left.\mathrm{A}^{\prime}\right)$.

${ }^{58}$ Interview with solicitor B, above $\mathrm{n} 41$.

${ }^{59}$ Interview with barrister $\mathrm{B}$, above $\mathrm{n} 36$.

${ }^{60}$ Interview with expert A, above $\mathrm{n} 43$.

${ }^{61}$ Interview with expert B, above $\mathrm{n} 45$.

62 Interview with Justice J Forrest, above n 30.
} 
ensured that each expert made an opening and closing statement, and had the opportunity to question others. He said that this ensured that passive personalities were not lost in the mix.63

The other participants had differing views about the impact of the personalities of the experts on the proceedings. One solicitor said that he "did not discern any difference in relation to the impact of different personalities as between joint or individual expert evidence sessions." 64 The barristers did not think that the impact of the personalities of the experts was any more significant than it was in other cases. One said even though personality plays a role in how the experts give their evidence, it was just something that the parties and the judge needed to anticipate and be alert to. ${ }^{65} \mathrm{He}$ explained that it is the judge's responsibility to manage personalities of the experts to ensure that evidence is given in an appropriate way:

[...] the Judge who has done the work before the concurrent evidence session will be in a position to evaluate whether the bombastic expert is answering the question or not, and if the timid expert is being timid, the judge can detect it and [...] reassure the expert that this is the place where they are going to get the free and final chance to express their actual view, and they better do it clearly without fear or favour because that's what's going to be the evidence. So, in Court it's not so much of a problem because it is open - the lawyers can see what's happening, [and] the judge can see what's happening $[\ldots]^{66}$

He said that there was no need to be "overly protective" about it: while it will give rise to problems on occasions, it is something that the parties and the Court can work together to address. ${ }^{67} \mathrm{He}$ did not think that "the risk requires any higher level or precautions than [...] the parties [being] alert to the risk" ${ }^{68}$

The other barrister said personality was not the critical issue, but rather that the level of expertise of the expert giving evidence was much more significant. ${ }^{9}$ He found that in concurrent evidence sessions "the witnesses that came across the best were the ones who were really on top of their science."70 He said that "even someone who had a quiet personality, [...] [if they] demonstrated they knew the science par excellence, they were going to be much more persuasive than a strong

\footnotetext{
63 Ibid.

64 Interview with solicitor B, above n 41 .

65 Interview with expert A, above $n 43$.

${ }^{66}$ Interview with barrister A, above $\mathrm{n} 35$.

67 Ibid.

68 Ibid.

${ }^{69}$ Interview with barrister B, above $\mathrm{n} 36$.

70 Ibid.
} 
personality who didn't really know that much when they were prodded or poked." 71 The experts who knew less about the topic "waffled" and "came unstuck a bit". 72

One solicitor said there "was a complete lack" of adverse impact from the personalities of experts during the concurrent evidence sessions. He explained that:

There was essentially an intellectual respect. I did worry about that in the court-administered process, but I think it is just the fear of the unknown more than anything. I had enough confidence that we'd picked people of great integrity and intellect, it was very unlikely they would be overborne by anyone. I understand the conceptual worry, but I didn't see it in this case. ${ }^{73}$

He said the "calibre of the people" involved in the sessions meant that they were not "people who, in an intellectual sense, were going to be easily overwhelmed". ${ }^{74}$

The difference in opinion between the two experts interviewed was particularly stark. One expert was not concerned, saying that:

While each expert had his own character, the process was very fair in allotting time for each one to make presentations without much interaction between the experts. There were a few inter-expert questions and these were mainly issues of technical methodology and fact checking. Almost invariably, these exchanges were done in a very courteous manner. ${ }^{75}$

The view of the other expert was quite different. He had the most difficulty with experts that "couldn't keep up" or were "inflexible in their thinking", saying they "consumed a lot of effort, and provided little to no insight into the science."76 He said that there appeared to be "a risk of personality bias in the court's conclusions dismissing work that was either bombastic, or presented poorly." 77 He said that the trial process took a toll on some of the experts, with some experts struggling with fatigue, particularly when faced with an "onslaught of continual cross examination". He said that one expert found it particularly challenging:

Poor [expert name] took a thrashing almost every day, and he was physically and emotionally exhausted by the end of proceedings. We were given fair warning that it was to be a marathon trial and cross-examination, but some people are not good at that sort of event. ${ }^{78}$

\footnotetext{
${ }^{71}$ Ibid.

72 Ibid.

${ }^{73}$ Interview with solicitor A, above $\mathrm{n} 58$.

${ }^{74}$ Ibid.

75 Interview with expert A, above $\mathrm{n} 43$.

${ }^{76}$ Interview with expert B, above n 45.

77 Ibid.

${ }^{78}$ Ibid.
} 
He said that the friendship he developed with the other experts made it "heartbreaking to watch them get torn apart in the stand" and "made me reluctant to assist in dismissing their work." $79 \mathrm{He}$ said that at times he "felt the whole process was immoral and my association with it, or at least my lack of opposition to the ruthlessness demeaning." 80 However, unlike some of the others he felt that he was able to "use the lenience and flexibility in the method of concurrent cross-examination to my advantage." 81

\section{Administrative issues}

The number of people in the room during a concurrent evidence session can make it difficult to ensure that everyone can properly participate in the session: one expert said he struggled to hear the judge properly in the courtroom as the judge did not always talk into the microphone. 82

Justice Forrest ordered that the experts be quarantined from the parties for the duration of the concurrent evidence session. His Honour said that this caused no difficulties, and if anything the experts were "delighted to be precluded from seeing the lawyers", and welcomed it. ${ }^{83}$ The legal practitioners were supportive of this decision. One solicitor described it as "appropriate" 84 , and the other solicitor said that while it did pose some administrative challenges, "the benefits far exceeded any difficulties." He explained that:

I think it is both the fact and the perception that this is truly their own opinion, unadulterated. It is mostly perception - experts who are inclined to be led by lawyers quickly get found out, I think, in the rigorous process that is a trial, but mostly it is perception. It gives a judge comfort it is genuinely the expert's view. I personally have no difficulty with it. ${ }^{85}$

One of the barristers described quarantining as "essential to the integrity of the process" and said it was no different to lawyers not being able to speak to an expert while they were being crossexamined. ${ }^{86}$ It was important not to contaminate the process. ${ }^{87}$ The other barrister agreed: he said it ensured there was "no funny business" and that it was "sensible, and it didn't impede things,

\footnotetext{
79 Ibid.

80 Ibid.

81 Ibid.

82 Interview with expert A, above $\mathrm{n} 43$.

83 Interview with Justice J Forrest, above n 30.

${ }^{84}$ Interview with solicitor B, above n 41 .

${ }^{85}$ Interview with solicitor A, above $\mathrm{n} 58$.

86 Interview with barrister A, above n 35 .

87 Ibid.
} 
and it meant that the experts were able to concentrate on their own opinions, which [...] believe it or not, the lawyers actually want." 88

The quarantining did pose some challenges for the experts. One expert said that while quarantining was "essential during the trial to avoid influence", he struggled when he was quarantined from one of his friends participating in a different concurrent evidence session. He said that as he knew this person's "written material intimately" he wanted to help them but was unable to. ${ }^{89}$ He thought "greater insight and more representative answers could have resulted from the relaxation of the quarantining [of experts from each other] during direct crossexamination."90

He said quarantining made it more difficult for the experts to be properly supported, particularly when the concurrent evidence session went across many weeks. He suggested "getting really strict with meal-times, bed times, forced exercise and returning home on most weekends just to stay sane and ready." 91 He said the experts did help each other in the process: he invited the other experts back to his accommodation during lunch breaks to "eat real food (bread, cheese, tomatoes, etc.) and talk sport". He said that:

This was a welcome relief from the cafes and court scene. I found it a welcome solace to have a picnic each day with people in a similar privilege and sufferance and it was an important part of my social day and health. However, I was very careful with hygiene: I took care each morning to leave the flat with no notes, reports, calculations or plots in clear view. We were all careful about the talk and spent time either chatting about other fields or catching up on newspapers. ${ }^{92}$

He thought that sometimes the social interaction was not so benign. He said that some experts who were in the same expert conference met with each other and "shared stories and technical discussion over a bottle or two of red wine." His said that:

This continued contact with each other resulted in people changing their opinions on some topics, and being more ready to defend or reinforce opinion on work that they had not contributed to or shown interest or previous opinion. This seemed like poor hygiene and I thought it was not entirely innocent i.e. some people were working the social play for influence. ${ }^{93}$

He suggested that the Court should pass on a "cautionary note" to experts taking part in concurrent evidence emphasising "the risks of talking out of school", and warning that they

\footnotetext{
${ }^{88}$ Interview with barrister $\mathrm{A}$, above $\mathrm{n} 35$.

${ }^{89}$ Interview with expert B, above $\mathrm{n} 45$.

${ }^{90}$ Ibid.

${ }^{91}$ Ibid.

92 Ibid.

${ }^{93}$ Ibid.
} 
should avoid direct discussion on the topic. ${ }^{94}$ Any such warning, however, should acknowledge the need for social support. 95

\section{Value of concurrent evidence}

The participants were generally positive about the value of the concurrent evidence sessions. None took the opportunity to question whether the expert evidence should have been given in the traditional manner, and all saw significant advantages with hearing all the experts on a particular issue at once. The lawyers said the number of experts and complexity of their evidence meant that giving evidence without using concurrent evidence would have been enormously challenging. It was harder for the experts to make this kind of assessment as they had not had the same amount of court experience as the legal practitioners. Nevertheless, one expert said that while he did not have any prior experience of traditional adversarial proceedings, he did watch a day of solo crossexamination during the trial. He thought "the subject, method and strategy employed by [the barrister] were a waste of time and exhausting." He said that "[r]elative to this the concurrent evidence and conclaves gave a significantly more accurate view of the experts' opinions."96

\section{CONCLUDING REMARKS}

The use of concurrent evidence in the Kilmore East bushfire proceeding appears to have been a success. The testimony of the participants supports the widely held view that it is a useful tool in cases with complex evidence and many experts. For the judge, it does require more work prior to the trial and the concurrent evidence session. The judge's preparation should include being familiar the expert material as well as preparing or assessing proposed agendas. However, the benefits are significant as it means that all the evidence on one topic is heard together and will therefore appear in the transcript together, making judgement writing much more straightforward. There are other advantages: the experts can question other experts and respond directly to the arguments raised, holding each other to account. The comments of one expert who gave evidence in the Kilmore East bushfire proceedings confirmed that experts are very aware of the competence of other experts, and use the opportunity of concurrent evidence to show the court that their view is the most persuasive. As one of the barristers said, the parties also benefit as there is someone with expertise in the subject matter that can catch the technical obfuscation or mistakes of the experts of the other side.

\footnotetext{
${ }_{94}$ Ibid.

95 Ibid.

${ }^{96}$ Ibid.
} 
The experience in the proceeding does indicate there are some issues with concurrent evidence that should be borne in mind. Larger concurrent evidence sessions that take a long time can be very demanding on everyone concerned. The resources and planning required to have so many experts in court at once are substantial. The court and participants should also ensure that adequate consideration is given to the well being of the experts. This is particularly the case when experts are quarantined as they are often away from home for long periods. Spending many days in a witness box, even alongside other people in a concurrent evidence session, is exhausting. The personality of the experts will impact on the concurrent evidence session, but this does not really pose a new challenge to the trial judge. It does not raise the same concerns as expert conferences (which occur behind closed doors) because any adverse interaction between the experts can be seen by the judge and the parties. It is interesting that some experts are as tactically minded and strategic as the lawyers, 'gaming' the concurrent evidence session in an attempt to convince the court that their view of the evidence is the best one.

There can be little doubt that in the Kilmore East bushfire proceeding, if the court had heard each of the nine experts who participated in the largest concurrent evidence session, separately and possibly months apart, it would have posed a substantial challenge to Justice Forrest and the lawyers to synthesise the results. It would have required them to revisit and closely familiarise themselves with the same scientific evidence multiple times during the proceeding. During judgement writing, it would have taken an enormous amount of work to bring all that material together to evaluate it and make factual findings. In these circumstances there is no doubt that concurrent evidence is a useful way of cutting down some of this work. The procedure should be considered by judges in all cases where there are multiple experts giving evidence on the same issues. 


\section{APPENDIX}

\section{A. Section one: view from the Victorian bench}

The four judges interviewed who did not participate in the Kilmore East bushfire proceeding acknowledged there was a place for concurrent evidence in modern civil litigation, but some expressed reservations about applying it too broadly. Justice Beach said that it was necessary to be a "bit careful" with concurrent evidence. He said that he had not presided over a case where he felt there was a need to hear evidence concurrently:

There's a lot to be said for just putting witnesses in the box one at a time and focusing on someone and saying 'Well, how do you justify this particular opinion in cross-examination?' [...] [P]eople have written since time immemorial [that] the loneliest place in this whole court complex is the witness box in any court where you're on your own, you're an expert, [and] you justify your professional opinion. ${ }^{97}$

His Honour added that there was a risk concurrent evidence could obscure whether an expert really knew the subject on which they were giving evidence:

[T] he expert witness who's not quite as well qualified as the others gets a chance to hide his or her lack of knowledge, while someone else speaks the real detail, and then she gets the chance to say 'Ah, yes, but you're wrong about this for that reason' without first of all having to have put the foundations in and demonstrate that they've got true expertise. ${ }^{98}$

Justice Almond also expressed some caution about the procedure. He said it was necessary to explore with the parties during the pre-trial process whether it would be appropriate to hear the evidence concurrently. ${ }^{99}$ This would allow the judge to evaluate the utility of the procedure in the particular case.100 His Honour added that the judge always reserves the right to change tack and hear the expert evidence individually if the judge thinks that would best promote justice in the case. ${ }^{101}$

Judges who had used the procedure acknowledged that the comprehensive preparation required could be demanding on the judge. Justice Almond said that engaging fully with the concurrent evidence session required a "considerable amount of preparation to gain an understanding of the real issues in dispute", including "a level of technical understanding by reading the reports in

\footnotetext{
${ }^{97}$ Interview with Justice Beach (2 September 2014, Supreme Court of Victoria, Melbourne).

98 Ibid.

${ }^{99}$ Interview with Justice Almond (13 October 2014, Supreme Court of Victoria, Melbourne).

100 Ibid.

101 Ibid.
} 
advance". 102 Preparation is important to ensure the judge is able to fully engage in the process, and to ensure the procedure is explained in detail to the expert witnesses who will be participating in the session. ${ }^{103}$ Ideally, this should include a description of the intended sequence of the evidence and how the court will ensure everyone will have an opportunity to be heard.104

\section{Level of judicial intervention}

As would be expected, views differed on what level of intervention from the bench was appropriate. Justice Hargrave said that "total" intervention from the bench was necessary for a concurrent evidence session to be effective. He said it was the judge's responsibility to manage it and "to work through it in a structure way, issue by issue". ${ }^{105} \mathrm{He}$ explained his standard approach:

The first thing is to divide it into the issues, to stage it, to go issue by issue. The second thing is that on each issue to summarise the Court's perception of what the agreement is and what the disagreement is and ask the expert to comment on that so that the judge knows he's got it right. The third thing is to ask them to comment upon each other's rival view where there is a disagreement, to ask questions between themselves and see if they can resolve anything by agreement at that stage. The judge, I think, then should also enquire and that sometimes leads to agreement being reached which wasn't reached in the conclave. Then lastly, the parties can ask some questions. I normally limit the questions just to that issue. Sometimes if I give leave to allow cross-examination as to credit on a particular issue but normally I would say save it up for the end [of the concurrent evidence session]. And then at the end of each issue, I then summarise where the evidence stands on that issue in the logical framework of issues and ask the experts to comment on that, and for a general comment they require on that issue and then we move on to the second issue. ${ }^{106}$

His Honour explained that this ensured that the individual issues did not overlap, and that the reasoning of the experts was set out in a clear and transparent manner. He said that despite this control, it was still "an informal process" and the experts had a considerable amount of autonomy as to how they interacted within the above structure. ${ }^{107} \mathrm{He}$ said informality made it more likely for the evidence to address the "real nub of the issue." 108 In addition, it does not prevent the parties

\footnotetext{
102 Ibid.

103 Ibid.

104 Ibid.

${ }^{105}$ Interview with Justice Hargrave (6 October 2014, Supreme Court of Victoria, Melbourne).

106 Ibid.

107 Ibid.

108 Ibid.
} 
from cross-examining as they see fit, it just ensures that it is done in a structured way and that it does not become needlessly adversarial.109

Justice Hargrave said that the reason for the judge exercising this level of control was the judge as the ultimate decision-maker, had to make sure that he or she understood the expert evidence presented. He endorsed the view that it was an advantage that for each issue "all the evidence [...] is in the joint report and one piece of transcript", which "makes the judge's judgment writing task much easier." 110 Further, with such a process there is "less room for error, at least in the sense of misunderstanding as to what the experts are actually saying." 111 He agreed there was "no question" that hearing evidence concurrently substantially shortens the trial.112

Justice Almond said that the most important concern for the judge was to ensure that each of the experts had a "fair opportunity to contribute" and that the judge "needs to be firmly in command of the issues between the parties who have provided expert reports". ${ }^{113} \mathrm{He}$ said proper preparation allows the judge to better control the flow of questions, which is essential to ensure the utility of the concurrent evidence session:

There needs to be a structured approach; otherwise it can become difficult for transcribers to identify the people who are engaging in what might be described as debate with the consequence that the evidence can become difficult to follow later on, on transcript. ${ }^{114}$

In contrast, Justice Croft said that "not a lot" of intervention was necessary. He said aside from having an agenda set, he would leave it to counsel to work through the issues. ${ }^{115}$ He explained:

I think in some respects it's better if you sit on the side [...] I don't really like the witness staring at me all day. I'm quite happy to see them interacting with counsel, and you often get a better view from the sidelines as to what's going on and to form a view, so I think to some extent that's a good way to do it in a [concurrent evidence session]. ${ }^{116}$

The difference in approach between the judges appears to be mostly dependent on the style of the trial judge, and what works for one may not work for all.

\footnotetext{
109 Ibid.

110 Ibid.

111 Ibid.

112 Ibid.

113 Interview with Justice Almond (13 October 2014, Supreme Court of Victoria, Melbourne).

114 Ibid.

115 Interview with Justice Croft (14 October 2014, Supreme Court of Victoria, Melbourne).

116 Ibid.
} 


\section{Impact of personalities of experts}

The judges acknowledged that the personalities of the experts could have an impact on the effectiveness of the concurrent evidence session, but were sure this could be managed by the Court. Justice Almond said the fear that personalities could adversely affect the concurrent evidence session was overstated as it just presented the judge with a challenge the judge would face with any witness. He explained that:

Part of the role of the judge is to make sure everybody has a fair opportunity to be heard, so that if somebody was dominating then it is really a judge's role to intercede to make sure that the less dominant person has a fair opportunity to contribute. Personality plays a part in the giving of evidence whether there's concurrent evidence or not. Strong personalities may give their evidence in a more robust fashion than other people. That doesn't mean that the judge will accede to the evidence given by the dominant personality. ${ }^{117}$

However, his Honour emphasised that the personality and behaviour of the experts sometimes did have a significant impact on the trial:

Sometimes experts giving evidence concurrently become irritated with each other. They may tend to slide off point into positional arguments with another party's expert. This can be distracting and indicates that the expert does not truly understand their role and duty to the court. I have become less of a proponent of concurrent evidence partly because I have had instances where the individuals themselves become argumentative. Although this can be readily controlled by judicial intervention, a base level of irritation existing between individual experts tends to compromise the quality of their evidence. If I thought there was likely to be a significant personality clash between experts I would tend not to allow the evidence to be given concurrently. Sometimes, it is just better to keep the experts apart. ${ }^{118}$

He said there were some useful indicators as to when this might occur. If there is a "lot of heat along the Bar table" it can be a sign that "the parties might end up having highly positional experts." 119 Another indication is the "tenor of the criticism directed to the other expert" in expert reports in reply or in joint reports. ${ }^{120}$ This can give a "strong signal that an expert might behave disparagingly or highly positionally at trial", and that was an "indicator to me as a judge that it may be preferable to keep the experts apart."121

\footnotetext{
117 Interview with Justice Almond (13 October 2014, Supreme Court of Victoria, Melbourne).

118 Ibid.

${ }^{119}$ Ibid.

120 Ibid.

121 Ibid.
} 
Justice Hargrave also said that managing the different experts could be "difficult" in a concurrent evidence session, but that it was usually apparent when there was a mismatch in personality or experience. ${ }^{122}$ He compared the situation to when the parties have barristers of differing levels of skill, and in particular hearings where an inexperienced barrister fails to ask the right question, and the judge has to step in to ensure that it is asked. It was about how the judge managed the situation, rather than being about stopping it from occurring. ${ }^{123}$

\section{B. Section two: methodology}

The primary source of material for this research project was gathered in interviews with judges of the Supreme Court of Victoria and some of the participants of the Kilmore East bushfire proceedings. The interviews were conducted in late 2014 and early 2015 in person and by letter and email. The judges selected were either involved in the proceeding (Justice Forrest) or were chosen as they represented a range of different views about the management of expert evidence (Justice Beach, Justice Croft, Justice Almond and Justice Hargrave). The participants from the Kilmore East bushfire proceeding who were interviewed were selected to ensure that the research took account of both the plaintiff and defendant sides, as well as covering the different roles within the proceeding. To this end, two barristers, two solicitors and two experts were interviewed. They agreed to be interviewed on the basis that they would remain anonymous due to the sensitive nature of some of their comments, and so all identifying information has been removed from their answers.

Interviews in person were semi-structured and the questions were focussed on the particular procedural challenges the court faced (for example "What was the impact of having a large number of experts giving concurrent evidence at the same time?"). Interviews conducted by email were by response to questions provided to the interviewees. The research project has some obvious limitations: it was not possible to interview all the judges of the Supreme Court or all the participants in the Kilmore East bushfire proceeding. It does not in any way assess the experience of the many plaintiffs, whose tragic experiences were the basis of the case. This paper is not intended to be a source of comprehensive empirical data. Rather, it aims to ensure the experience of the court during these significant proceedings is recorded and that any lessons that were learnt during the proceeding are captured for posterity. It is hoped that this record will be of value to other judges of the Supreme Court of Victoria, as well as judges in other jurisdictions, and to legal

\footnotetext{
122 Interview with Justice Hargrave (6 October 2014, Supreme Court of Victoria, Melbourne).

${ }^{123}$ Ibid.
} 
practitioners. One of the aims of the project was to better understand how newer methods of managing expert evidence were used by the Court and perceived by those who were using them and the Kilmore East bushfire proceeding was a good opportunity to assess some of these issues. 


\section{University Library}

\section{- M M I E R R V A gateway to Melbourne's research publications}

Minerva Access is the Institutional Repository of The University of Melbourne

Author/s:

McKenzie, S

Title:

Concurrent Evidence in the Kilmore East bushfire proceeding

Date:

2016-04-13

Citation:

McKenzie, S. (2016). Concurrent Evidence in the Kilmore East bushfire proceeding. Supreme Court of Victoria.

Persistent Link:

http://hdl.handle.net/11343/91568 